\title{
A REVISION OF THE TASMANIAN FRESHWATER CRAYFISH GENUS ASTACOPSIS HUXLEY (DECAPODA: PARASTACIDAE).
}

\author{
by Premek Hamr
}

(with three text-figures)

HAMR, P., 1992 (31:x): A revision of the Tasmanian freshwater crayfish genus Astacopsis Huxley (Decapoda: Parastacidae). Pap. Proc. R. Soc. Tasm. 126: 91-94. https://doi.org/10.26749/rstpp.126.91 ISSN 0080-4703. 28 Undercliffe Ave, Hamilton, Ontario, L8P 3HI, Canada: formerly Department of Zoology, University of Tasmania.

During a broad study of the biology of the freshwater crayfishes in the Tasmanian genus Astacopsis, two distinct forms of Astacopsis franklinii were recognised. These "forms" were found to differ in terms of their general morphology and distribution. As a result, the taxonomy of Astacopsis has been revised to re-establish the threespeciesoriginallydescribed by Ellen Clark. Astacopsisfranklinii Gray has been divided into two separate species, the eastern Astacopsis frankliniiand the western Astacopsis tricornis, while the status of Astacopsis gouldi remains unaltered. Key Words: Astacopsis, Tasmania, distribution, taxonomy.

\section{INTRODUCTION}

The members of the genus Astacopsis, which include the world'slargest freshwater crayfish (and thereforeinvertebrate) species, are associated with riverine and lacustrine habitats throughout Tasmania (Swain et al. 1982). Taxonomically and ecologically their closest relatives are the crayfishes of the genera Euastacus and Astacoides (Hobbs 1987,1988, Riek 1972). The genus was first erected by Huxley in 1878 but earlier accounts and descriptions of crayfish now placed in this genus are available (Gray 1845, Gould 1870). Perhaps the earliest representation of Astacopsis is a painting made in 1832 by the convict artist William Buelow Gould in his "Book of Fishes". The pictured crayfish is clearly identifiable as the large western form of $A$. franklinii, probably from the lower reaches of the Gordon River.

The existence of several Tasmanian varieties of crayfishes within the genus was recognised by Smith $(1909,1912)$ but he retained a single specific name, $A$. franklinii, for all Tasmanian members of the genus. Clark (1936) separated the Australian and Tasmanian members of the genus, assigning the former to a new genus Euastacus while reserving Astacopsis for the latter. At the same time, she revised Astacopsis adding two new species: $A$. gouldi (from northern Tasmania) and $A$. tricornis (from the Lake St Clair region). A. franklinii was retained and used for the smaller Astacopsis from the Launceston and Hobart regions. Riek (1969) added another species, separating $A$. franklinii into $A$. fluviatilis (from southern Tasmania) and $A$. franklinii (from northern Tasmania). Swain et al. (1982) revised the genus and reduced the number of species from four to two by including $A$. fluviatilis and $A$. tricornis within $A$. franklinii.

A. gouldi, the giant freshwater crayfish or "lobster", as it is called locally, is the world's largest known crayfish, attaining weights of more than three kilograms (Smith 1909, Lynch 1967, Hobbs 1988). The species is restricted to the north of Tasmania, where it can be found in streams, rivers and reservoirs draining into the Bass Strait, as well as in the Arthur River system in the extreme northwest (Swain et al. 1982).

A. franklinii is found throughout most of Tasmania (Swain et al. 1982) in, or in association with streams, rivers and lakes. Although generally smaller than $A$. gouldi, it appears to vary greatly in size and spininess. In their re-examination of the various morphological characters, Swain et al. (1982) found that the variation in spininess and size had a geographical basis. It will be shown in this study that this variation is, in fact, at least partly due to the occurrence of two distinct forms within $A$. franklinii, and it is further proposed that these two forms should be treated as two separate species.

\section{METHODS}

The specimens used in the diagnosis of the species of Astacopsis were collected during a broad study of population structure and reproductive biology of the crayfishes in this genus (Hamr 1990). The morphometric descriptions and measurements were obtained from individuals collected at various sites throughout Tasmania between 1985 and 1989. Individuals from numerous populations throughout the range of each species were examined and compared.

Crayfish were captured using baited nets and hand lines, as well as by hand, using snorkelling equipment and turning over rocks and submerged logs.

Morphometric measurements for all specimens used in this revision were measured with Vernier callipers and recorded to the nearest tenth of a millimetre, including carapace length $(\mathrm{CPL}=$ rostrum tip to back edge of carapace) which was used as a standard measure. Rostral width (RW) refers to the maximum width of the rostrum between the eyes. The inter-ocular width was chosen as it was least affected by growth-related changes in the morphology of the rostrum. The mean-size adjusted inter-ocular rostral width refers to the ratio between rostral width and carapace length (RW/CPL). Populations of $A$. franklinii from Hobart Rivulet and the Lake St Clair region (Clarence Lagoon) were used in the rostral morphometry comparisons because they correspond to the original Astacopsis species described by Ellen Clark (1936).

Some of the specimens examined, as well as new distributional information, were obtained from Dr A.M.M. Richardson's taxonomic collection at the University of Tasmania, as well as from surveys conducted by the Inland Fisheries Commission (Tasmania). 


\section{RESULTS AND DISCUSSION}

During the examination of Tasmanian populations of Astacopsis franklinii, two distinct forms were recognised. These forms appear to have non-overlapping distributions (fig. 1) and were found to differ in terms of their general morphology as well as their size at maturity (Hamr 1990). Because of these differences, these forms are here referred to as two species.

The most reliable morphological characters separating the species of Astacopsis were found on the rostrum. A. gouldi can be clearly distinguished from the other two species by the presence of a median rostral carina, while $A$. franklinit can be separated from $A$. tricornis on the basis of rostral width and depth (fig. 2) Figure 3A \& B shows the difference in the inter-ocular rostrum width between the species. In addition, the mean-size adjusted inter-ocular rostral widths of $A$. tricornis (mean $=0.126, \mathrm{~s}, \mathrm{~d} .=0.013, \mathrm{n}=35)$ and $A$. franklinii $($ mean $=0.11$, s.d. $=0.006, \mathrm{n}=51$ ) were found to be significantly different $(t=-7.92, \mathrm{df}=84, \mathrm{p}<0.0001)$.

Although some differences in rostral morphology were noted by previous authors (Riek 1936, Swain et al. 1982), no characters other than the presence or absence of the median rostral carina and the morphology of spines on the lateral carinae were examined.

As shown by Swain et al. (1982), the exact number and location of spines are clearly unreliable taxonomic characters for separating Astacopsis species. There is, however, a clear difference in overall spininess between $A$. franklinii and $A$. tricomis, especially in adult individuals. This difference was shown by Swain et al. (1982) who stated: "Examination of the material in our collection suggested that much of the variation in general spininess of $A$ franklinii had a geographical basis, with a reduction in spininess both from west to east and north to south". Similarly they found that "large animals were present only in collections from river systems draining north or west". This corresponds directly with the distribution of the two species previously grouped under $A$. franklinii as identified in this study (fig. 1). Their failure to detect the clear east-west separation was probably due to sampling discrepancies (such as low numbers of crayfish from the northeastern region) and the large size/age range of animals in their samples. As it is generally more difficult to recognise the specific characters in juveniles of closely related crayfish species, the best results in keying out members of the genus Astacopsis are obtained when adults are compared.

The findings of this study suggest that the two previously recognised forms of $A$. franklinii can be treated as separate species. The "western form" description in this study corresponds closely to the initial description of Astacopsis tricornis by Clark (1936), who recognised differences between the southeastern and western populations of $A$. franklinii. Her sampling of the western form, however, was restricted to the Lake St Clair region and therefore, she failed to recognise the wider distribution of this species. Nevertheless, it is suggested that $A$. tricornis should be re-erected and assigned to the larger, western form of the present A. franklinii.

The differences between the two species arising from A. franklinii and the revised key for the genus Astacopsis are described as follows:

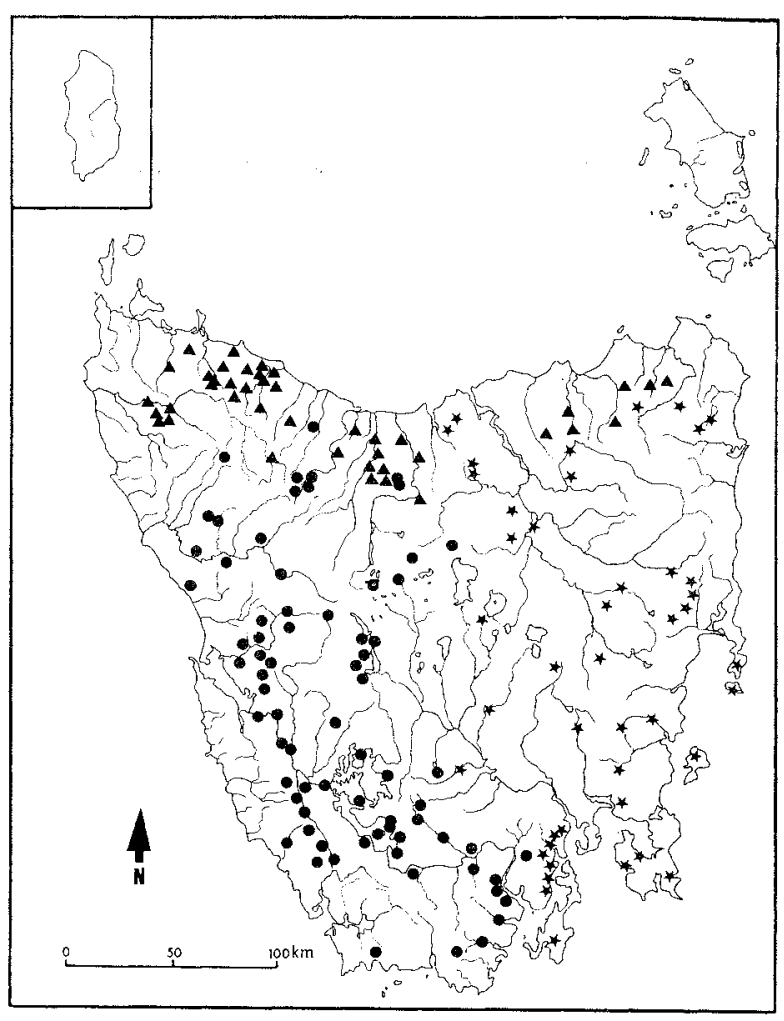

FIG. 1 - Distribution of Astacopsis gouldi (triangle), Astacopsis franklinii (star) and Astacopsis tricornis (circle) in Tasmania.
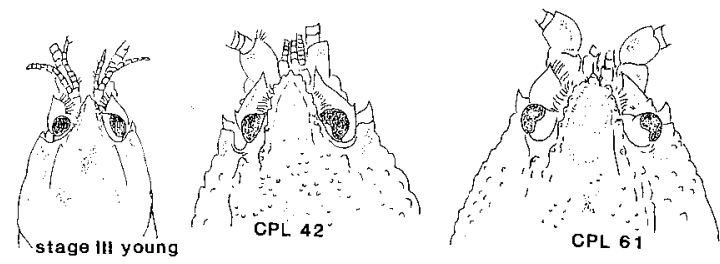

A.
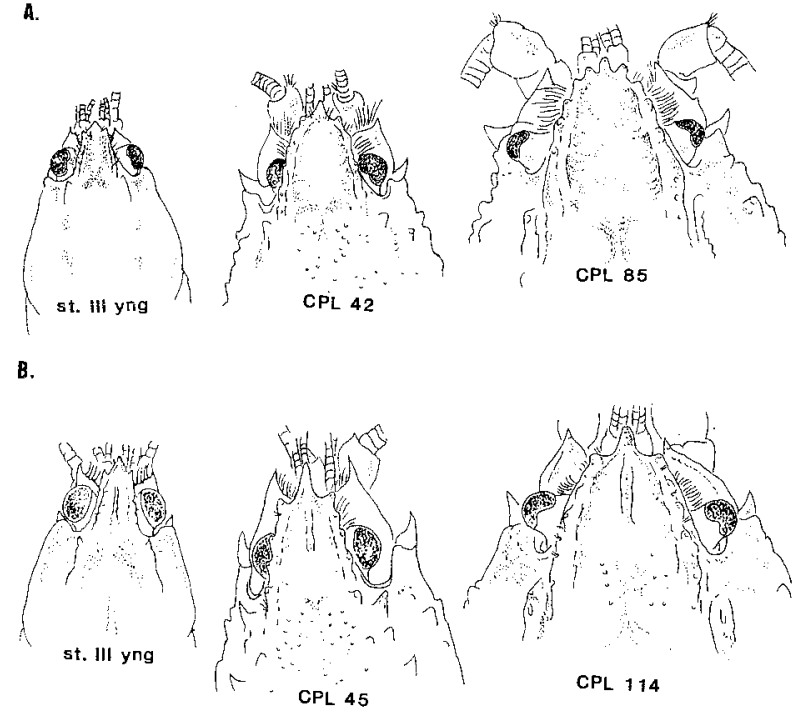

c.

FIG. 2 - Comparison of rostral morphology (stage III young to large adult) in Astacopsis franklinii $(A)$,

Astacopsis tricornis $(B)$ and Astacopsis gouldi (C). CPL = carapace length. 


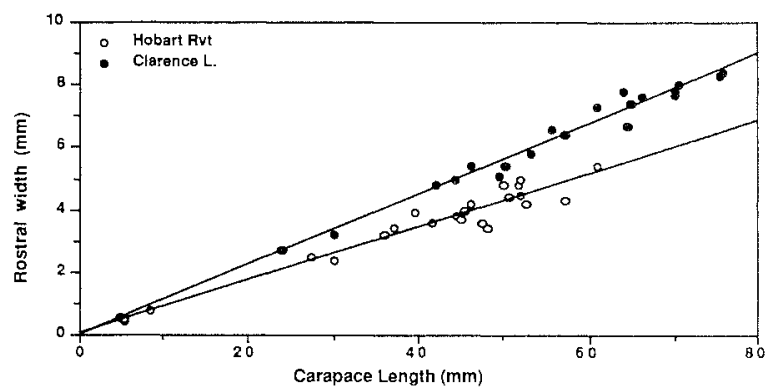

A.

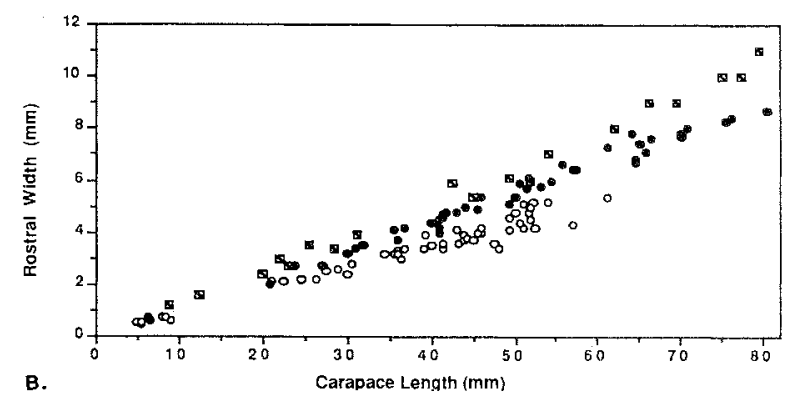

FIG. 3 - (A) The relationship between interocular rostral width and carapace length in Astacopsis franklinii, from Hobart Rivulet (open circle; $y=0.055+0.085 x, r^{2}=0.953$ ) and Astacopsis tricornis, from Clarence Lagoon (closed circle; $y=0.024+0.113 x, r^{2}=0.971$ ). (B) The relationship between interocular rostral width and carapace length in Astacopsis franklinii (open circle; $y=2.0379 e-2+8.7363 e-2 x, r^{2}=$ 0.952), Astacopsis tricornis (closed circle; $y=0.17927+$ $0.10614 x, r^{2}=0.981$ ), and Astacopsis gouldi (open square with dot; $y=-0.21848+0.13415 x, r^{2}=0.990$ ) in various Tasmanian populations.

\section{KEY TO THE GENUS ASTACOPSIS}

1a. Rostrum divided by a median longitudinal carina .......... A. gouldi Clark.

1b. Rostrum without a median longitudinal carina ......... 2 .

2a. Rostrum broad, concave, U-shaped. Adults large with numerous, prominent spines and tubercles

A. tricornis Clark.

2b. Rostrum narrower, flat, V-shaped. Adults small with less prominent spines and tubercles..... A. franklinii Gray.

\section{SPECIES DESCRIPTIONS}

\section{Astacopsis franklinii}

Astacus franklinii Gray, 1845: 409.

Astacopsis tasmanicus Smith, 1909: 65.

Astacopsis franklinii v ar. tasmanicus Smith, 1912: 156.

Astacopsis franklinii Clark, 1936:34; 1939:119; Riek, 1969 : 898.

Astacopsis fuviatilis Riek, 1969: 912.

Astacopsis franklinii Swain et al., 1982: 700.

Diagnosis

Adults small (largest specimen: $61 \mathrm{~mm}$ CPL, $0.060 \mathrm{~kg}$ ); Rostrum narrower anteriorly, $\mathrm{V}$-shaped, shallow (flat), apex terminated in single blunt spine; lateral rostral carinae blunt, with 6-7 low tubercles; small tubercle at base of carinae (fig. 2); eyes large; body armature relatively heavy, spines less sharp overall, tubercles on brachiostegites small and un iform; great chelae short and stout with large palm and short fingers, covered with small depressions (on palm) and tubercles (on fingers); large spine on merus; held horizontally with respect to substrate; sternal keel blunt, lateral processes low, unsculptured, little tuberculation; male genital papilla with complete calcified tube, separated from basal portion of coxopodite in mature individuals; tube sculptured, less cylindrical; telson calcified, without transverse suture, with single spine on lateral margins; uropods calcified uniformly in immature individuals and adult males, decalcified distally in mature females; juveniles: basically light orange brown; adults: basically dark brown, tubercles orange, underside light orange brown; blue morphs are infrequently found among adults.

\section{Distribution}

Eastern half of Tasmania, approximately east of a line from the Wellington Range in the south through the midlands to the Asbestos Range in the north (fig. 1). New locality records: Fortescue Bay, Lagoon Creek, Allens Creek (Tasman Peninsula); Guy Fawkes Rivulet; Appledorf Creek; Tyenna River; Captain Cook Creek tributary (Bruny Island), Falls Creek tributary (Bruny Island); Browns Creek (Asbestos Range N.P.); Swan Rivulet tributary; Crocketts Creek (Schouten Island); Eastern Rivulet, Jimmy Rivulet and Cooks Beach-Mt Graham track (Freycinet Peninsula).

\section{Astacopsis tricornis}

Astacopsis tricornis Clark, 1936: 36; 1939: 120. Astacopsis franklinii Swain et al., 1982: 700.

\section{Diagnosis}

Adults medium to large (largest specimen: $148.4 \mathrm{~mm}$ CPL, $1.00 \mathrm{~kg}$; rostrum broad, deep (concave), strongly U-shaped, apex terminated in several spines; lateral rostral carinae sharp, raised with 5-6 raised tubercles (fig. 2); eyes large; body armature heavy; spines on abdomen, chelae and walking legs, large and sharp in specimens of all sizes; prominent raised tubercles of variable size and sharpness, laterally on brachiostegites and cephalic region; great chelae large; fingers long, covered with prominent tubercles/spines; prominent sharp spine on merus; palm without depressions; held horizontally with respect to substrate; sternal keel sharp, lateral processes raised, sculptured, tubérculate with winglike appearance in adults; male genital papilla with complete calcified tube, separated from basal portion of coxopodite in mature individuals; tube more cylindrical, less sculptured, with prominent raised keel; telson calcified, without transverse suture, with single spine on lateral margins; uropods calcified uniformly in immature individuals and adult males, decalcified distally in mature females; colour — juveniles: very light brown, sometimes grey; underside ivory; adults: basically brown to light brown; tubercles and spines yellow; those on brachiostegites especially prominent; blue marking on brachiostegites and cephalic region present in very large individuals; underside ivory; blue morphs not noted. 


\section{Distribution}

Western half of Tasmania, approximately from the Huon River in the south through the western edge of the Central Plateau to the Gog Range in the north (fig. 1). New locality records: Pigsty Ponds; Pelverata Falls; Arve River tributary; creek draining in to Reservoir Lake; Meander River; Croanna Creek; Prince Rivuler; Weld River; Harlequin Hill (burrow in buttongrass plain); Sandfly Creek (Scotts Peak road); Scotts Peak (rainforest creek draining into Lake Pedder); Swampy Creek; Dozer Creek; two un-named creeks running into Bonnett Bay, Lake Pedder; Serpentine River (below dam); Melaleuca Creek (Melaleuca); Giblin River; Lake Meston; Clarence Lagoon; Lake Dixon; Lake Margaret; Ring River tributary (near Murchison Highway); Murchison River; Princess River; Comstock Creek; Heazlewood River tributary; Jean Brook; Eel Hole Creek.

\section{Astacopsis gouldi Clark}

Astacus sp. Gould, 1870: 42.

Astacopsis franklinii Huxley, 1978: 764; Smith, 1909: 65; 1912: 154.

Astacopsis gouldi Clark, 1936: 35; 1939: 119; Riek, 1969: 898; Swain et al., 1982: 701.

\section{Diagnosis}

Adults very large (largest specimen: $214 \mathrm{~mm}$ CPL, $4.0 \mathrm{~kg}$ ); rostrum broad, relatively shallow, $\mathrm{V}$ to U-shaped, apex sharp, terminated in single prominent spine, longitudinal carina in centre of rostrum (generally well-defined but can be weak on some small specimens), lateral rostral carinae raised with 36 blunt tubercles on each side, blunt spine at base of rostral carinae (fig. 2); eyes large; body armature heavy; spines and tubercles on chelae, walking legs, carapace and abdomen; cephalothoracic and abdominal spines much sharper in smaller specimens becoming blunter in large specimens (fig. 2); great chelae stout and very large, especially in adult males (adult female chelae less robust, thinner and more elongate), outer surface of both fingers covered with small, yellow tubercles/spines; prominent sharp spine on merus; held horizontally with respect to substrate; sternal keel moderately sharp, with a sharp, ventrally facing spine on process between second and third periopods; male genital papilla with complete calcified tube, separated from basal portion of coxopodite in mature individuals; telson calcified, without transverse suture, with single spine on lateral margins; uropods calcified uniformly in immature individuals and adult males, decalcified distally in mature females; colourjuveniles: basically brown with green mottling, spines and tubercles white, underside of cephalothorax ivory; adults: basically dark brown-green, sometimes almost black, chelae brown with greenish tips, tubercles and spines yellow; characteristic blue marking laterally on brachiostegites and cephalic region; blue morphs are often found among adults, in these the basic overall colour is bright blue.

\section{Distribution}

The known distribution of A. gouldi is shown in figure 1 . New locality records: Pearly Brook (Horwitz, pers.comm.); St Patricks River (introduced population); Garden of Eden Creek; Gunns Plains Caves; Lake Barrington; West Gawler
River; Inglis River tributary (near Henrietta); Big Creek; Hellyer River; Detention River; Wilsons Creek; Sumac Rivulet.

In Gunns Plains caves, specimens ranging in carapace lengths from $55 \mathrm{~mm}$ to $147 \mathrm{~mm}$ were collected from the creek running through the cave as far as $300 \mathrm{~m}$ from the tourist entrance. From this study, as well as the observations of Mr Des Wing, the cave caretaker, it appears the crayfish live and breed inside the cave (Mr Wing reports seeing berried females as well as small juveniles deep within the cave). This constitutes the first report of such a phenomenon in Tasmania.

\section{ACKNOWLEDGMENTS}

This study was supported by an internal research grant from the University of Tasmania. I thank all people who helped in the collection of crayfishes.

\section{REFERENCES}

Clark, E., 1936: The freshwater and land crayfishes of Auscralia. Mem. Nat. Mus. Vict. 10:5-58.

Clark, E., 1939: Tasmanian Parastacidae. Pap. Proc. R. Soc. Tasm. (1938): $117-128$

Gourd, C., 1870: On the distribution and habits of the large freshwater crayfish (Astacus sp.) of the northern rivers of Tasmania. Pap. Proc. R. Soc. Tasm. 1870: 42-44.

GOULD, W.B., 1932: BOOK OF FISHES. A sketchbook containing 35 watercolours of fishes found at Macquarie Harbour (studies for Dr de Little). Allport Library and Museum of Fine Arts, State Library of Tasmania, Hobart, Tasmania.

GRAY, J., 1845: Description of some new Australian animals. In Eyre, E.J. (Ed.): Journals of Expeditions of Discovery into Central Australia and Overland from Adelaide to King George Sound, in the years 1840-41. Vol 1: Appendix. T. and W. Boone, London: 407-11.

Hamr, P., 1990: Comparative reproductive biology of the Tasmanian freshwater crayfishes Astacopsis gouldi (Clark), Astacopsis franklinii (Grey), and Parastacoides tasmanicus (Clark). Unpubl. PhD thesis, Zoology Department, University of Tasmania, Hobart.

Hosbs, H.H., 1987: A review of the genus Astacoides (Decapoda: Parastacidae). Smithson. Contrib. Zool. 443: 1-50.

HobBs, H.H., 1988: Crayfish distribution, adaptive radiation and evolution. In Holdich, D.M. \& Lowery, R.S. (Eds): FRESHTWATER CRAYFISH: BIOLOGY, MANAGEMENT AND EXPLOITATION. Croom Helm, London: 52-82.

LyNCH, D.D., 1967: Synopsis of biological data of the giant freshwater crayfish Astacopsis gouldi Clark 1936. Inland Fisheries Commission Publ., Tasmania.

RIEK, E.F., 1969: The Australian freshwater crayfish (Crustacea: Decapoda: Parastacidae), with descriptions of new species. Aust. J. Zool. 17: 855-918.

Riek, E.F., 1972: The phylogeny of the Parastacidae (Crustacea: Astacoidea), and description of a new genus of Australian freshwater crayfishes. Aust. J. Zool. 20: 369-389.

SmITH, G., 1909: The freshwater Crustacea of Tasmania. Trans. Linn. Soc. London (Ser. 2) 11: 61-92.

Smith, G., 1912: The freshwater crayfishes of Australia. Proc. Zool. Soc. 10: 144-171.

Swain, R., Richardson, A.M.M. and Hortle, M., 1982: Revision of the Tasmanian genus of freshwater crayfish Astacopsis Huxley (Decapoda: Parastacidae). Aust. J. Mar. Freshw. Res. 33: 699-709.

(accepted 1 May 1992) 